\title{
Discursos sobre a democracia racial em Cuba e no Brasil: Tramas de gênero, raça e sexualidade na literatura (1933-1978)
}

\author{
Los discursos sobre la democracia racial en Cuba y Brasil: Marcos de \\ género, la raza y la sexualidad en la literatura (1933-1978) \\ Discourses on racial democracy in Cuba and Brazil: Plots of gender, race \\ and sexuality in literature (1933-1978)
}

\section{Giselle Cristina dos Anjos Santos. ${ }^{1}$}

\begin{abstract}
Resumo
Esta comunicação tem como foco os discursos sobre a democracia racial em Cuba e no Brasil, considerando os aspectos de gênero, raça e sexualidade. Para isto serão analisadas as obras Écue-Yamba-Ó (1933) de Alejo Carpentier e Gabriela, cravo e canela (1958) Jorge Amado.
\end{abstract}

Palavras-Chave: democracia racial; literatura; Cuba; Brasil.

\section{Resumen}

Este documento se centra en los discursos de la democracia racial en Cuba y Brasil, teniendo en cuenta los aspectos de género, la raza y la sexualidad. Para ello se analizarán las obras Écue-Yamba-Ó (1933) de Alejo Carpentier y Gabriela, clavo y canela (1958) de Jorge Amado.

Palabras clave: democracia racial; literatura; Cuba; Brasil.

\section{Abstract}

This communication focuses on the discourses about racial democracy in Cuba and Brazil, considering gender, race and sexuality aspects. For this, the works Écue-Yamba-Ó (1933) by Alejo Carpentier and Gabriela, harpsichord and cinnamon (1958) Jorge Amado will be analyzed.

Key words: racial democracy; literature; Cuba; Brazil.

\section{1- Introdução}

Esta pesquisa tem como objetivo analisar os discursos sobre a democracia racial em Cuba e no Brasil, considerando os aspectos de gênero, raça e sexualidade envolvidos na

\footnotetext{
${ }^{1}$ Doutoranda em História Social pela Universidade de São Paulo (USP). Mestra em Estudos de Gênero e Teoria Feminista pela Universidade Federal da Bahia (UFBA). Bacharela em História pela Pontifícia Universidade Católica de São Paulo (PUC-SP). USP, São Paulo, Brasil, E-mail: santos.gisellea@gmail.com Trabalho apresentado no I Seminário Latino-Americano de Estudos em Cultura - SEMLACult, Foz do Iguaçu/PR, Brasil, 2017.
} 
construção dessas narrativas, por meio da literatura. Para isto serão analisadas como fontes as obras de Alejo Carpentier (1904-1980) e Jorge Amado (1912-2001), em particular, os livros Écue-Yamba-Ó (1933) do primeiro, e Gabriela, cravo e canela (1958) do segundo autor. Além disso consideramos a discussão de outras produções de Amado e Carpentier, tais como ensaios, conferências e entrevistas.

Para a análise das fontes de pesquisa faremos uso das seguintes categorias teóricoanalíticas e conceitos: representação social, gênero, raça, sexualidade e interseccionalidade.

Quanto a categoria de representações sociais utiliza-se a formulação de Roger Chartier (1988), que a entende como figuras graças as quais o presente pode adquirir sentido, ao permitir ver uma coisa ausente.

No que tange a discussão de gênero, partilhamos das considerações de Joan Scott (1995), que compreende que gênero é um elemento constitutivo das relações sociais baseadas nas diferenças que distinguem os sexos, instituindo-se como uma forma primária das relações significantes de poder.

No âmbito da sexualidade, adotamos como referência as proposições de Foucault (2010), que entende que as práticas eróticas são socialmente construídas a partir de relações de poder, articuladas por mecanismos e dispositivos de saber-poder-prazer. Para ele a sexualidade não é dada naturalmente em relação ao corpo biológico, mas construída na cultura e pela cultura.

Já no que diz respeito à categoria raça, partilhamos da definição conceitual do antropólogo Michel Wieviorka (2007) que não a compreende a partir de uma noção biológica, mas como um construto histórico-social que legitimou práticas de subordinação e hierarquização de diferentes grupos sociais. Assim, embora a raça não exista em termos biológicos, está presente no imaginário social por meio de classificações hierarquizadas de grupos e indivíduos.

Desta forma, para compreender como se estruturam e relacionam as diferentes dimensões da opressão de gênero, raça e sexualidade nos contextos estudados, utiliza-se como referência o conceito de interseccionalidade proposto por Kimberlé Crenshaw. Segundo ela, a categoria interseccional "busca capturar as conseqüências estruturais e dinâmicas da interação entre dois ou mais eixos da subordinação” (CRENSHAW, 2002, p. 177). Tal perspectiva demonstra-se relevante por desconstruir a conceituação aritmética da interação entre diferentes sistemas de desigualdades. 


\section{2- Debates sobre a democracia racial em Cuba e no Brasil}

Existem muitas correlações entre a história de Cuba e do Brasil, sobretudo no âmbito das relações raciais. Algumas são: nos dois países o regime escravista perdurou por mais de 300 anos; Cuba e Brasil tiveram os sistemas escravistas mais importantes das Américas durante o século XIX, além disso foram os últimos países do continente a abolirem a escravidão, que ocorreu somente em 1886 e 1888 respectivamente; nesses dois contextos houve um amplo debate público empreendido por intelectuais sobre qual seria o destino da população negra após a abolição; assim como em Cuba, no Brasil foram desenvolvidas políticas para a promoção da imigração europeia, com a finalidade de alcançar o branqueamento da população. Ademais, tanto em Cuba como no Brasil vigoraram regimes com caráter ditatorial e viés populista entre as décadas de 1930 e 1940; e a figura da mulata foi edificada como ícone da identidade nacional nos dois países em meados do século XX (CUBAS, 2011; PINO, 2002). Portanto, são inúmeras as correlações históricas entre Cuba e Brasil $^{2}$.

Dentre tais semelhanças destaca-se que, segundo Oliveira (2012), desde o final do século XIX e começo do XX existia um efervescente debate na América Latina e Caribe entre intelectuais preocupados em forjar uma ideia de nação homogênea para os seus respectivos países; e isto não foi diferente no contexto cubano e brasileiro. O debate em questão estava pautado por uma concepção biológica, baseado no discurso eugenista, que considerava como inferiores negros, indígenas e mestiços, a maioria da população dessas duas sociedades. Isto levou com que muitos intelectuais, políticos e artistas considerassem a inviabilidade da construção de nações efetivamente desenvolvidas ${ }^{3}$. Essas noções eram quase unânimes e estavam consolidadas no campo intelectual dos dois países, até as contribuições do sociólogo Gilberto Freyre no Brasil e do etnólogo Fernando Ortiz em Cuba. Cada um, em seu respectivo cenário, inovou ao afirmar que brancos, negros e indígenas contribuíram de forma positiva para a formação da identidade nacional brasileira e cubana.

Freyre e Ortiz elaboraram trabalhos inovadores no campo das ciências sociais, e segundo Arroyo (2003) e Oliveira (2012) existem muitas similaridades nos conceitos e

\footnotetext{
${ }^{2}$ David Thelen (2009) defende que se os fenômenos extrapolam as fronteiras dos Estados-nações, é fundamental a constituição de análises históricas com enfoque transnacional.

${ }^{3}$ Neste cenário do final do século XIX e início do XX, entre os intelectuais que participaram ativamente do debate sobre o lugar social da população negra em Cuba e no Brasil, é possível destacar dentre os brasileiros: Nina Rodrigues, Euclides da Cunha, Oliveira Vianna, entre outros (MUNANGA, 2008). E no contexto cubano, ressaltam-se os nomes de José Antonio Saco, Betancourt Cisneros e Francisco Arango y Parreño (DE LA FUENTE, 2001).
} 
argumentos formulados pelos dois autores. Ademais, o discurso formulado por esses pensadores nas obras "Casa grande e senzala" e "Contrapunteo cubano del tabaco y el azúcar" (publicadas em 1933 no Brasil e 1940 em Cuba) foi utilizado para edificar a concepção hegemônica sobre as relações raciais e a identidade nacional, em seus respectivos países. Os argumentos a respeito da mestiçagem racial e cultural presentes nessas obras foram utilizados de acordo com os interesses das elites dos dois países para afirmar a imagem de sociedades harmônicas, nas quais haveria integração entre os diferentes grupos raciais (ARROYO, 2003; DE LA FUENTE, 2001, OLIVEIRA, 2012). Contudo, para o sociólogo Michael Hanchard (1995) esse discurso que afirmava a vigência da democracia racial, visava instituir a concepção de uma identidade nacional homogênea, camuflando as desigualdades estruturais colocadas entre negros e brancos na distribuição e acesso aos recursos, tanto em Cuba como no Brasil.

A partir das pesquisas dos historiadores Alejandro De La Fuente (2001) e Petrônio Domingues (2005) é possível identificar a existência de proximidades entre os argumentos de defesa da existência de relações raciais harmônicas, concepção que dá base ao discurso da identidade nacional nos dois países.

O sociólogo Antônio Sérgio Guimarães (2001) ao traçar uma análise da construção e disseminação da expressão democracia racial no Brasil, ressalta a existência de diferentes leituras e significados vigentes a partir de meados do século $\mathrm{XX}$, pautadas pelas noções de ideal, pacto e mito, utilizadas a depender dos interesses de seus interlocutores. Todavia, segundo o autor, a concepção mais adotada, seja com a finalidade de defesa ou de crítica, foi da democracia racial como mito, baseado na ideia de um fenômeno já consolidado.

Apesar de ter sido uma expressão menos utilizada no contexto cubano, diversos autores - principalmente estrangeiros ou cubanos residindo no exterior - também analisaram os discursos sobre democracia racial em Cuba. De La Fuente (2001, p. 51) afirma que a versão cubana da democracia racial no contexto do início da republica teve duas implicações importantes. A primeira foi a concepção de que em Cuba não existia nenhum tipo de problema racial, e a segunda, foi a noção de que se persistia alguma assimetria racial, os responsáveis eram os próprios negros.

De acordo com Florestan Fernandes (1972) o argumento que alicerça o mito da democracia racial no Brasil se encontra no processo de mestiçagem da população, uma particularidade importante deste cenário. Contudo, este fenômeno também consiste como característico da ilha de Cuba (ORTIZ, 2002). Esta prática que marca ambos os países se estabeleceu historicamente com a interação entre homens e mulheres de grupos raciais 
distintos por meio de relações sexuais, consentidas ou não, tendo como consequência a reprodução de filhos mestiços. Mas, além da interação entre diferentes grupos, demonstra-se necessário considerar que a mestiçagem foi marcada por diversas hierarquias sociais no âmbito, especialmente, de gênero, classe, raça e sexualidade. Pois tal processo conformou-se por meio da premissa de "miscigenação seletiva", com o envolvimento de mulheres negras e indígenas e homens "brancos", excluindo as mulheres brancas e os homens negros e indígenas. Ou seja, tanto os marcadores de raça, como de gênero e sexualidade foram essenciais para a constituição desta prática social.

O antropólogo Peter Wade (2013, p. 47) afirma que "El mestizaje está completamente permeado por el género, en el concepto y la práctica.". Uma vez que,

sus significados incluyen el intercambio cultural y la transmisión, el mestizaje está profundamente impregnado de nociones de reproducción sexual, genealogía, familia y parentesco, todas las cuales involucran ideas sobre las relaciones entre hombres y mujeres, en las cuales es central el sexo (WADE, 2013, p. 47).

Ou seja, para Wade (2013) o processo de mestiçagem está intrinsicamente pautado por relações de gênero. Ademais, para diversos autores (DE LA FUENTE, 2001; FERNADES, 1972) a mestiçagem estaria na base dos argumentos que alicerçam os discursos sobre a democracia racial. Neste sentido questionamos, seria possível afirmar que, para além dos pressupostos raciais, o gênero também foi preponderante na constituição dos discursos sobre a democracia racial? E mais, qual teria sido o papel da mulher negra e mulata na construção dos discursos sobre democracia racial na sociedade cubana e brasileira?

O próprio Wade (2013) destaca que a interação entre a mestiçagem e o gênero foi reconhecida timidamente e ainda é pouco explorada nos estudos. E se o debate sobre este fenômeno negligenciou a discussão de gênero, tal ausência nas análises dos discursos sobre a democracia racial fica ainda mais aparente. Poucas investigações analisaram efetivamente a importância da articulação entre os marcadores de gênero, raça e sexualidade para a conformação dos discursos sobre a democracia racial e a identidade nacional no cenário latino-americano (WADE, 2013), e mais especificamente no contexto cubano e brasileiro. Desta forma, trazer luz para este debate a partir de um enfoque interseccional demonstra-se como uma potencial contribuição para a historiografia.

\section{3- Tramas de gênero, raça e sexualidade em Alejo Carpentier e Jorge Amado}

O debate intelectual sobre a construção da identidade nacional e as especificidades da dinâmica racial na sociedade cubana e brasileira, influenciou a produção discursiva de 
diversos agentes sociais, como músicos, artistas, poetas e literatos ao longo do século XX. Ao abordar a condição deste último agente social e as correlações entre a história e a literatura, Nicolau Sevcenko (2003) defende que as transformações sociais são registradas pela literatura, pois os fenômenos históricos se refletem "no campo das letras, insinuando modos originais de observar, sentir, compreender, nomear e exprimir.” (SEVCENKO, 2003, p. 286).

Segundo Sandra Pesavento (2008) as narrativas literárias expressam as percepções e inquietudes que mobilizam os agentes sociais de um determinado contexto histórico. Por este motivo a literatura evidencia-se como fonte de análise privilegiada para a história, ao passo que a discussão sobre os autores e seu contexto pode trazer pistas sobre uma determinada época.

Foi neste sentido que realizamos a escolha dos autores das obras literárias elegidas como fontes de análise para esta pesquisa. No tocante da trajetória desses escritores, destacase a respeito da vida e da obra de Carpentier que o mesmo nasceu em 1904, mas não é clara se a sua origem é cubana ou europeia ${ }^{4}$, embora racialmente seja branco. Ainda muito jovem participou de movimentos vanguardistas dos anos 1920, integrando o Grupo Minorista neste período $^{5}$. A sua obra foi reconhecida e premiada pelas recriações históricas, a ênfase à cultura latino-americana, a referência à mitologia e a estética do "real maravilhoso"6. Ele morreu em 1980 em Paris, onde exercia a função de embaixador do governo revolucionário cubano desde 1966.

Écue-Yamba-Ó foi o primeiro romance de Carpentier. A primeira versão do livro foi redigida em 1927, enquanto o autor estava na prisão em La Habana - devido à perseguição do governo de Machado. O livro foi reescrito em Paris e teve a sua primeira publicação em Madri em 1933. A obra narra a história de uma família negra e podre que vive no campo. A

\footnotetext{
${ }^{4}$ Carpentier afirmava ter nascido em La Habana e ser fruto do casamento entre uma pianista russa e um arquiteto francês, e teria estudado na França, Bélgica, Áustria e Rússia. Após a sua morte surgiram indícios de que o autor teria nascido na Suíça, em uma família humilde que imigrou para Cuba, se instalando no povoado de Alquizar.

${ }^{5}$ Em 1920 começou a se reunir em La Habana um grupo de jovens artistas e intelectuais de diferentes orientações político-ideológicas, mas que compartilhavam um forte sentimento anti-imperialista e a inconformidade com o cenário político. Este coletivo de vanguarda intelectual passou a se denominar como Grupo Minorista. Devido as críticas ao governo do presidente Gerardo Machado, muitos integrantes do grupo foram alvo da repressão do Estado, vários foram presos ou se exilaram. Em 1928 houve a desintegração do grupo (UXÓ, 2010).

${ }^{6} \mathrm{O}$ real maravilhoso, enquanto sub-gênero literário criado por Carpentier (2002), não define divisões entre a realidade e o sobrenatural. Embora conectado à concretude da história da América, ao mesmo tempo, essa vertente deu margens à transgressão da realidade. Assim, foi apresentada uma nova estética para as narrativas sobre o cenário latino-americano, já que o real maravilhoso considera a própria natureza do continente como surreal e fantástica.
} 
personagem principal da trama é o negro Menegildo Cué, que se envolve com a linda mulata Longina.

Posteriormente, Carpentier fez críticas ao seu primeiro romance, ao qual classificou como um livro marcado pelas "perplexidades e hesitações que um processo de aprendizado implica” (CARPENTIER, 1988, p. 6). Apesar da posição do autor, existem muitos aspectos relevantes nesta obra, que se configura como uma crônica socioeconômica e política da sociedade cubana do período (MIAMPIKA, 1997). Além disto, segundo Zurbano (2006, p.113) existe no livro "una valorización, hasta entonces inédita, del hombre negro cubano, su cultura y de una de sus religiones".

Já, no âmbito da discussão sobre o Brasil, a respeito da vida e da obra de Amado, destaca-se que o mesmo nasceu no interior da Bahia em 1912 e era filho de um fazendeiro de cacau. Embora fosse socialmente branco, ele se auto classificava enquanto mestiço (CALIXTO, 2011). Amado possui uma obra vasta e recebeu inúmeras premiações.

Segundo Calixto (2011) nessa produção extensa, Gabriela, cravo e canela (1958) e Tendas dos Milagres (1969) são considerados fundamentais para compreender o processo de sacralização do autor e de sua narrativa ao patamar de ícones da brasilidade. Foi a partir de Gabriela que Amado se consagrou efetivamente, este seria o seu livro mais conhecido, com sucesso de público e crítica imediatos, quando foi lançado os vinte mil exemplares publicados esgotaram em duas semanas. Esta é a obra mais traduzida do autor, disponível em vinte e nove idiomas. Além disso, foi muito premiada, inclusive com o Prêmio Jabuti por ter sido o livro que gerou mais adaptações para o cinema, televisão, fotonovela, dança e quadrinhos (CALIXTO, 2011). Ou seja, Gabriela teve grande repercussão no imaginário social brasileiro.

Em entrevista, Amado afirmou que ao construir Gabriela, protagonista da obra, buscou "criar uma mulher que fosse símbolo da mulher brasileira" (GOLDSTEIN, 2000, p. 163). Para cumprir tal representação, a personagem foi idealizada como mulata, sensual, alegre, simples, iletrada, solidária e trabalhadora. Contudo, existem interpretações divergentes acerca da imagem desta personagem, passando de objeto sexual silenciado à ícone da emancipação feminina (JÚNIOR, 1982; PUPO, 2009).

No que se refere a inserção dos dois autores no cenário intelectual de seus respectivos contextos, vale ressaltar que Carpentier tinha uma relação de amizade com Ortiz, desde a década de 1920. O próprio Carpentier falou a respeito da influência do pensamento orticiano no princípio de sua carreira: 
recuperación de tradiciones despreciadas por toda una burguesía. Interesarse por el negro, en aquellos años, equivalía a adoptar una actitud inconformista, por tanto, revolucionaria. (CARPENTIER, 1972, p. 52 apud UXÓ, 2010, p. 165)

Podemos aferir daí o tamanho da influência de Ortiz na obra de Carpentier. Tal inspiração foi importante a ponto de Carpentier se apropriar do conceito de transculturação ${ }^{7}$, concebido por Ortiz, fazendo referência ao mesmo com frequência (ORTIZ, 1989). O interesse, no entanto, era mútuo, Ortiz também era conhecedor da produção de Carpentier. E por sinal, o livro Écue-Yamba-Ó foi elogiado por Ortiz, que o definiu como uma exceção na abordagem do folclore negro cubano (ORTIZ, 1989).

Todavia, para além dos paralelos com a visão presente na obra de Ortiz ao usar o conceito de transculturação ${ }^{8}$, a concepção de Carpentier sobre a mestiçagem, assume características particulares, visto que ademais da noção positiva acerca da mestiçagem étnica e cultural, este processo assume uma conotação pautada pela estética do real maravilhoso:

Este suelo americano fue teatro del más sensacional encuentro étnico que registran los anales de nuestro planeta: encuentro del indio, del negro, y del europeo de tez más o menos clara, destinados, en lo adelante, a mezclarse, entremezclarse, establecer simbiosis de culturas, de creencias, de artes populares, en el más tremendo mestizaje que haya podido contemplarse nunca (CARPENTIER, 1976, p. 3 apud ORTIZ, 1989, p. 16).

Carpentier denomina a mestiçagem como "encontro" "sensacional". Entretanto, segundo Gonzalez (1984) as tensões e a violência marcaram este processo de interação. Desta forma, se a visão romantizada da mestiçagem seria a base do ideário sobre a democracia racial (WADE, 2013; MALDONADO-TORRES, 2007), demonstra-se oportuno analisar qual a concepção de Carpentier sobre a mestiçagem e a democracia racial, e como tais noções foram representadas em sua obra.

Já, a respeito da inserção de Amado no cenário intelectual de sua época, destaca-se que da mesma forma que Carpentier foi influenciado por Ortiz, Amado também foi inspirado pela produção intelectual de Freyre, a quem foi apresentado pessoalmente em 1932. Segundo Calixto (2011) a partir do lançamento de "Casa grande e senzala” (1933), no ano posterior a

\footnotetext{
${ }^{7}$ O conceito de transculturação proposto por Ortiz em 1940 no livro "Contrapunteo cubano del tabaco y el azúcar", já demonstrava suas bases fundamentais desde trabalhos publicados em 1913. A concepção de trânsitos culturais é fundamental para a definição do conceito proposto pelo autor: "No hubo factores humanos más trascendentes para la cubanidad que esas continuas, radicales y contrastantes transmigraciones geográficas, económicas y sociales de los pobladores, que esa perenne transitoriedad de los propósitos y que esa vida siempre en desarraigo de la tierra habitada, siempre en desajuste con la sociedad sustentadora. Hombres, economías, culturas y anhelos todo aqui se sintió foráneo, provisional, cambiadizo, 'aves de paso' sobre el país, a su costa, a su contra y a su malgrado." (ORTIZ, 2002, p. 81).

${ }^{8}$ Segundo Ángel Rama (2004), a transculturação é uma característica das narrativas literárias no contexto da América Latina e do Caribe.
} 
este encontro, a questão racial ganhou mais ênfase na obra de Amado, sob a nítida influência do pensamento freyriano.

Para a antropóloga Ilana Goldstein (2000), ainda que o tema racial fosse uma constante na obra de Amado, a concepção sobre o mesmo passou por mudanças ao longo do tempo, entre a fase em que estava engajado em fazer literatura proletária (1933-1954) e a sua fase posterior. A historiadora Lilia Schwarcz (2009) afirma que foi a partir de Gabriela que a defesa da democracia racial assumiu expressividade na sua obra:

(...) se Freyre foi um dos "pais da ideia" — ou ao menos aquele que a batizou —, Jorge Amado foi seu grande artista e divulgador, sobretudo a partir de meados da década de 1950, quando rompe com o stalinismo e entra em sua "fase tropical", inaugurada em 1958 com Gabriela, cravo e canela. Em seus livros, tudo parece ter resultado da mistura: as culturas, as religiões, o sangue dos diferentes grupos, a história, as festas, as relações afetivas, a cultura popular, a culinária, as religiões. (SCHWARCZ, 2009, p. 39)

Ou seja, de acordo com Schwarcz, Amado não foi apenas influenciado pelo pensamento freyriano de defesa do mito da democracia racial, ele se tornou o "grande" "divulgador" de tal concepção que entendia o Brasil como sinônimo de um paraíso racial, e Gabriela teria sido um grande estandarte para a divulgação deste imaginário.

Assim, a materialização do discurso sobre a democracia racial e a identidade nacional teria se consolidado no imaginário brasileiro a partir da figura de uma mulher mulata e não por meio da imagem de um homem mestiço, como se deu em outros contextos (GUTIÉRREZ, 2010). Em Cuba ocorreu um fenômeno muito parecido, a figura da mulata foi edificada como ícone da cubanidade no começo do século XX, por meio da literatura, poesias e canções (BLANCO, 2006). Para Leclercq (2004), a mulata foi consolidada enquanto referência simbólica da unidade nacional em Cuba.

Deste modo, a partir das referências mencionadas fica explícito que Amado e Carpentier estavam inseridos no movimento literário de seus respectivos países, ao mesmo tempo que estavam em contato com os debates presentes na esfera política e intelectual. Isto se coloca devido a interligação dos campos da política e da cultura (SIRINELLI, 1996).

A construção de um discurso positivo sobre o fenômeno da mestiçagem, por si só, já evidência uma possível concordância com os argumentos de defesa do mito da democracia racial. Tal concepção, ao conferir ênfase aos aspectos harmônicos da interação entre os diferentes grupos raciais em Cuba e no Brasil, invisibilizou as tensões e práticas de violência que recaíram especialmente sobre a figura das mulheres negras e mulatas, que ocuparam historicamente no imaginário social a condição ambígua de ícone sexual, instituído 
simultaneamente por representações de atração e repulsa (BLANCO, 2006; GONZALEZ, 1984).

\section{Referências}

AMADO, Jorge. Gabriela, cravo e canela. São Paulo, Companhia das Letras, 2008.

ARROYO, Jossianna. Travestimos culturales. Literatura y etnografía en Cuba y Brasil. Pittsburgh, Universidad Pittsburgh, 2003.

BLANCO, Melisa. El ritmo del azúcar. Una epistemología de la mulata cubana. In

CALIXTO, Carolina Fernandes. Jorge Amado: diálogos político-culturais e identidade nacional. (Dissertação Mestrado em História). Universidade Federal Fluminense, UFF, 2011.

CARPENTIER, Alejo. Écue-Yamba-Ó. Trad. Mustafa Yazbek. São Paulo, Brasiliense, 1988. Lo barroco y lo real maravilloso. In. HERNÁNDEZ, Rafael; ROJAS, Rafael. Ensayo cubano del siglo XX. México (D. F.): Fondo de Cultura Económica, p. 333-356, 2002.

CHARTIER, Roger. A História Cultural: Entre Práticas e Representações. Lisboa: Difel, 1988.

CRENSHAW, Kimberlé. Documento para o encontro de especialistas em aspectos da discriminação racial relativos ao gênero. Revista Estudos Feministas, Florianópolis, v.10, n.1, p.171-188, 2002.

CUBAS, Pedro Alexander Hernández. O Brasil e Cuba, 1889/1902-1929: o debate intelectual sobre as relações raciais. (Tese de doutorado) Universidade Federal da Bahia, Faculdade de Filosofia e Ciências Humanas, CEAO-UFBA, 2011.

DE LA FUENTE, Alejandro. Una nación para todos. Raza, desigualdad y política en Cuba 1900-2000. Madrid: Editorial Colibrí, 2001.

DOMINGUES, Petrônio. O mito da democracia racial e a mestiçagem no Brasil (1889-1930). Diálogos Latinoamericanos, Aarhus, $\mathrm{n}^{\circ}$ 10. p 115-131, 2005.

FERNANDES, Florestan. O negro no mundo dos brancos. São Paulo, Difel, 1972.

FOUCAULT, Michel. História da sexualidade I. A vontade do saber. São Paulo: Graal, 2010.

FREYRE, Gilberto. Casa-grande \& senzala: formação da família brasileira sob o regime da economia patriarcal. São Paulo: Global, 2006.

GOLDSTEIN, Ilana Seltzer. O Brasil best seller de Jorge Amado: literatura e identidade nacional. São Paulo, SENAC, 2000.

GONZALEZ, Lélia. Racismo e sexismo na cultura brasileira. Revista Ciências Sociais Hoje, Anpocs, 1984, p. 223-244. 
GUIMARÃES, Antonio Sérgio Alfredo. Democracia Racial: o ideal, o pacto e o mito. Novos estudos CEBRAP, n. 61, nov. 2001, p. 147-162.

GUTIÉRREZ, Horacio. Exaltación del metizo. La invención del roto chileno. Revista Universum. Universidad de Talca, ${ }^{\circ}$ 25, vol. 1, 2010, p. 122 -139.

GUTIÉRREZ, Pedro Juan. Trilogia suja de Havana. São Paulo: Alfaguara Brasil, 2008.

HANCHARD, Michael. Fazendo a exceção: narrativas de igualdade racial no Brasil, no México e em Cuba. Estudos Afro-Asiáticos, n.28, out. 1995, p. 203-217.

JÚNIOR, Teófilo Q. Preconceito de cor e a mulata na literatura brasileira. São Paulo, Ática, 1982.

LECLERCQ, Cécile. El lagarto en busca de una identidad. Cuba: identidad nacional y mestizaje. Madrid: Iberoamericana, 2004.

MALDONADO-TORRES, Nelson. Del mito de la democracia racial a la descolonización del poder, del ser, y del conocer. 2007. Disponível em: https://globalstudies.trinity.duke.edu/wpcontent/themes/cgsh/materials/events/DelMito.pdf Acesso: fev. 2016.

MIAMPIKA, Landry-Wilfrid. Ficción y mitos de origen africano en "Ecué-Yamba-Ó" y "El Reino de este mundo". Estudios de historia social y económica de América, 1997, n.15, p. 309-328.

MUNANGA, Kabengele. Rediscutindo a mestiçagem no Brasil: identidade nacional versus identidade negra. Belo Horizonte: Autêntica, 2008, $3^{\circ}$ ed.

OLIVEIRA, Emerson Divino Ribeiro. Gilberto Freyre e Fernando Ortiz: Cultura, Identidade Nacional e História (1906-1948). Tese de Doutorado, História, Universidade Federal de Goiás, p. 231, 2012.

ORTIZ, Fernando. Contrapunteo cubano del tabaco y el azúcar. La Habana: Ed. Ciencias, S/D.

. Los factores humanos de la cubanidad. In. HERNÁNDEZ, Rafael; ROJAS, Rafael. Ensayo cubano del siglo XX. México (D. F.): Fondo de Cultura Económica, p. 74-99, 2002.

ORTIZ, María Salvadora. El mestizaje como identidad latinoamericana en El recurso del método de Alejo Carpentier. Revista de Filología y Lingüística de la Universidad de Costa Rica, vol. 15, n.1, 1989, p.15-30.

PESAVENTO, Sandra Jatahy. História e história cultural. Belo Horizonte: Autentica, 2008, $2^{\circ} \mathrm{ed}$.

PINO, Julio Cesar. Fernando Ortiz y Gilberto Freyre: Racismo, democracia racial revolución. Estudios - Revista de Investigaciones Literarias y Culturales, año 10, n. 19, ene-jul. 2002, p. 73-89. 
PUPO, Joana d'Arc Martins. A construção da subjetividade feminina brasileira em Gabriela, cravo e canela na passagem do séc. XIX para o séc. XX. Uniletras, Ponta Grossa, v. 31, n.2, p. 115-131, jul./dez. 2009.

RAMA, Ángel. Transculturación narrativa en América Latina. Madrid, Siglo XXI, 2004.

SANTOS, Giselle dos Anjos. A participação das mulheres no Estado socialista cubano (1959 a 1980). (Pesquisa de iniciação cientifica) Pontifícia Universidade Católica de São Paulo, PUC-SP, 2009.

Mulheres negras em Cuba: Representações sociais em tempos de crise (1990-2012). (Dissertação de mestrado) Universidade Federal da Bahia, Faculdade de Filosofia e Ciências Humanas, PPGNEIM-UFBA, 2013.

SEVCENKO, Nicolau Literatura como missão: Tensões sociais e criação cultural na Primeira República. São Paulo, Companhia das Letras, 2003.

SCHWARCZ, Lilia Moritz. O artista da mestiçagem. In GOLDSTEIN; SCHWARCZ. Caderno de leituras: o universo de Jorge Amado. São Paulo, Companhia das Letras, 2009, p. 34-45.

SCOTT, Joan Wallach. Gênero: Uma Categoria Útil para a Análise Histórica. Educação e Realidade, Porto Alegre, v. 20, n. 2, jul-dez., p. 71-99, 1995.

SIRINELLI, Jean-François. "Os intelectuais”. in: RÉMOND, René. Por uma história política. Rio de Janeiro: Ed. UFRJ/Ed. FGV, 1996.

THELEN, David. Replanteamiento de la historia desde una perspectiva transnacional. In: Azuela; Palacios (coord.). La mirada mirada: transculturalidad e imaginarios del México revolucionario, 1910-1945. México: El Colegio de México. p. 299-309.

UXÓ, Carlos. Representaciones del personaje del negro en la narrativa cubana. Una perspectiva desde los estudios subalternos, Madrid: Verbum, 2010.

ZURBANO, Roberto. El Triángulo invisible del siglo XX cubano: raza, literatura y nación. Revista Temas, La Habana, n.46 p. 111-123, 2006.

WADE, Peter. Racismo, democracia racial, mestizaje y relaciones de sexo/género. Tábula Rasa. Bogotá, Colombia, n.18: 45-74, enero-junio 2013.

WIEVIORKA, Michel. O racismo, uma introdução. São Paulo: Perspectiva. 2007. 